
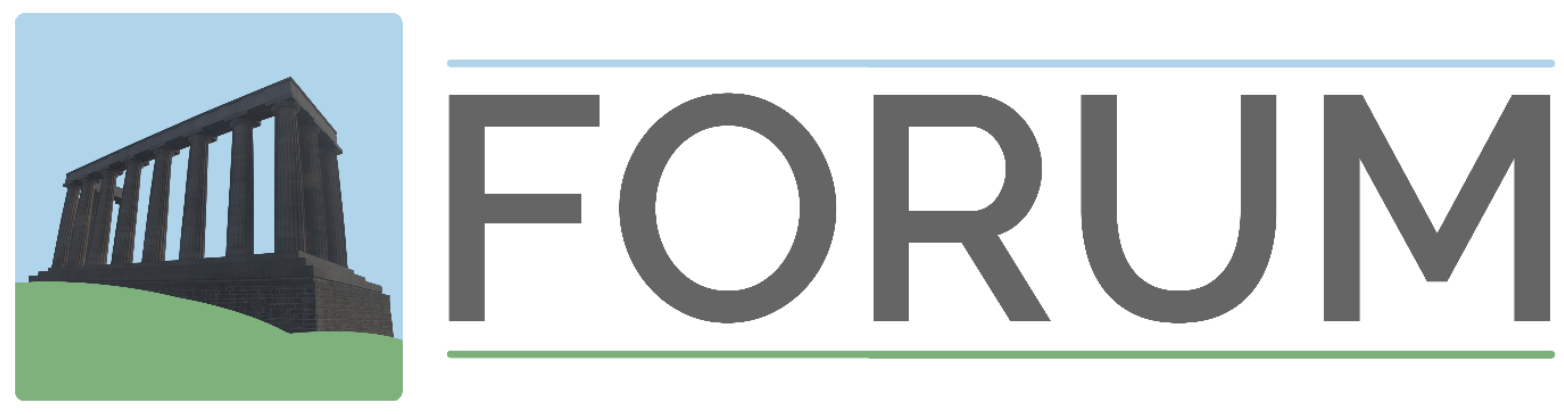

University of Edinburgh

Postgraduate Journal of Culture and the Arts

Issue 32 | Autumn 2021

Title

The Contemporary Art of the Nature Morte in the Age of Artificial Life Forms: The Metafictional Illusion of Life in Installation Art and Jeanette Winterson's Frankissstein

Author

Publication

Issue Number

Issue Date

Publication Date

Editor
Audrey Chan

FORUM: University of Edinburgh Postgraduate Journal of Culture \& the Arts 32

Autumn 2021

$01^{\text {st }}$ October 2021

Erin Walter

FORUM claims non-exclusive rights to reproduce this article electronically (in full or in part) and to publish this work in any such media current or later developed. The author retains all rights, including the right to be identified as the author wherever and whenever this article is published, and the right to use all or part of the article and abstracts, with or without revision or modification in compilations or other publications. Any latter publication shall recognise FORUM as the original publisher. 


\title{
The Contemporary Art of the Nature Morte in the Age of Artificial Life Forms: The Metafictional Illusion of Life in Installation Art and Jeanette Winterson's Frankissstein
}

\author{
Audrey Chan \\ University of Edinburgh
}

Observing the artistic response to the illusional nature of artificial life forms in the field of installation art, contemporary writers often allude to conceptual artworks through ekphrastic means to "grasp the texture of the contemporary real" (Virilio 4) in a technologically "transformative moment" (Boxall 4). A "reality hunger" for the contemporary brings together a "burgeoning group of interrelated [...] artists in a multitude of forms of media" (Shields 3) to experiment new forms across disciplines through ekphrasis, which "strikes to explode" the "stuffed package" of a culture "containable with its shaped word" (Krieger 233). In her essay "Art Objects" (1995), Jeanette Winterson shows her interest in contemporary conceptual art as she writes that "the true artist is interested in the art object as an art process" and establishing a connection to the future instead of being interested in the final product (12). Her definition of art coincides with that of conceptual art as it seeks to analyse "the ideas underlying the creation and reception of art" (Shanken 433), and thus takes on the framework of the meta-critical process from conceptual art with "the use of scientific concepts and technological media both to question their prescribed applications and to create new aesthetic models" (Shanken 434). Deriving from the artistic landscape of conceptual installation art and its interactions with science, Winterson borrows the subject of the nature morte and the metafictional framework to address the clashes between artificial life forms and the human civilisation by alluding to artworks such as those of Damien Hirst in her novel Frankissstein (2019) when writing about cryonic bodies: "It's a little like an art installation in here isn't it? Have you seen Damien Hirst's pickled shark in a tank?" (106). Based on the interdisciplinary interrelations between installation art and contemporary literature, this paper will read the dialogue between Winterson's ekphrastic subject of the nature morte in Frankissstein and contemporary installation art, including works of Hirst, Cai Guo-Qiang, and Guillaume Paris, as a response to the rise of artificial life forms with respect to their metafictional and illusional nature as AI will become "fully self-designing" (Winterson 73). 


\section{Introduction}

The subject of the still life has appeared throughout the history of art and can be traced back to the fifteenth century. The representation of the still life has evolved across centuries, from the pre-modern religious allegories in Hans Memling's Vase of Flowers (1480) to the blurred boundaries between life and death following the two world wars as in Andy Warhol's postmodernist work Ten-Foot Flowers (1967). Moving on to the age of technology, contemporary installation art touches on the concept of technologically-moulded reality by creating a dimension of "techno-nature" that metaphysically blends technology and our perceived 'natural' reality together (Crowther \& Wünsche 234-235). For example, William Latham's Mutation X Raytraced (1991-1992) shows a collection of three-dimensional virtual sculptures of non-existing hybrid animals (see fig. 1) that expose the audiences to the horror of the 'unnaturalness' and lifelessness of the artificial beings.

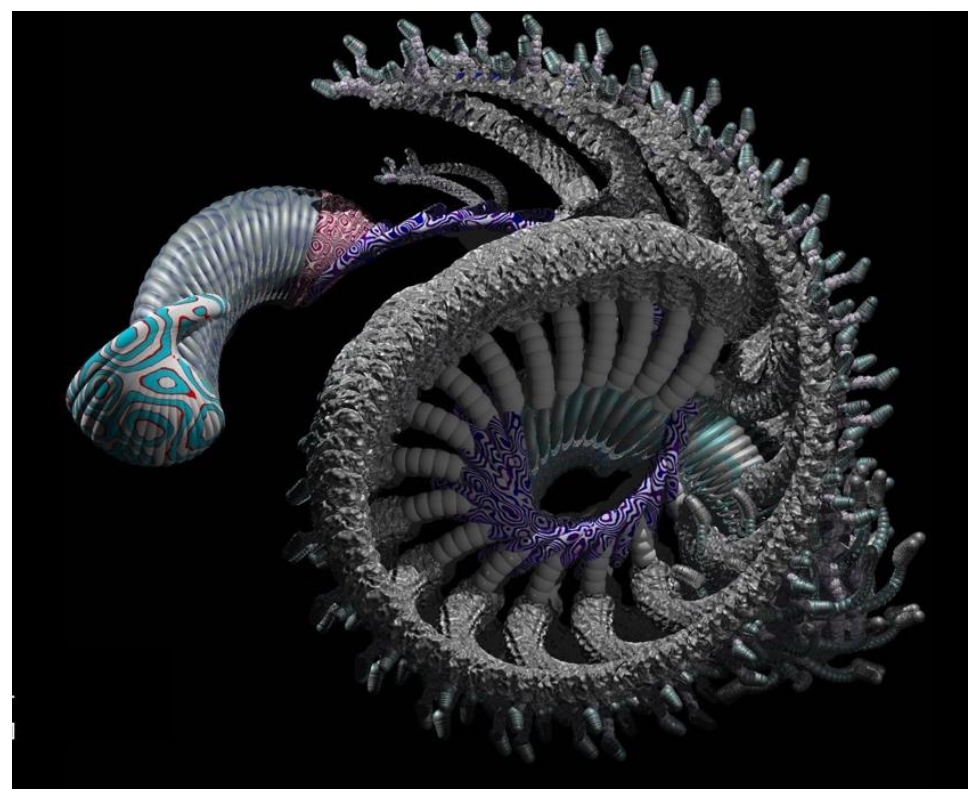

Figure 1. Latham, William. Mutation X Raytraced. 1991-1992,

Mutator VR, mutatorvr.co.uk/portfolio/mutation-x-raytraced-bluewilliam-latham-1992/?portfolioCats=35.

In this sense, in response to the sensationalizing of death in modernity (Petry 18), the contemporary representation of the still life reacts against the "waning of affect" (Jameson 10) embodied in the coldness of artificial intelligence by bringing the notion of death close to the viewers. Given the contemporary focus on the authenticity of life in the technology-dominated 
world of installation art, I will henceforth employ the French term nature morte ${ }^{1}$ instead of 'still life' in this essay as it suggests the "layered symbolism of the genre and its poignant reminders of the transience of life and the ever-present threat of death" (Petry 6).

Observing the artistic response to the illusional nature of artificial life forms in the field of installation art, contemporary writers often allude to conceptual artworks through ekphrastic means to "grasp the texture of the contemporary real" (Virilio 4) in a technologically "transformative moment" (Boxall 4). Ekphrasis, therefore, is a useful literary device in contemporary writing as it is "a trailblazer for later approaches to intermedial and multimodal forms of expression" (Armstrong \& Langås 2). A "reality hunger" for the contemporary brings together a "burgeoning group of interrelated [...] artists in a multitude of forms of media" to experiment with new forms across disciplines through ekphrasis (Shields 3), which "strikes to explode" the "stuffed package" of a culture "containable with its shaped word" (Krieger 233). In her essay "Art Objects" (1995), Jeanette Winterson shows her interest in contemporary conceptual art as she writes that "the true artist is interested in the art object as an art process" and establishing a connection to the future instead of being interested in the final product (12). Her definition of art coincides with that of conceptual art as it seeks to analyse "the ideas underlying the creation and reception of art" (Shanken 433). It thus takes on the framework of the meta-critical process from conceptual art with "the use of scientific concepts and technological media both to question their prescribed applications and to create new aesthetic models" (434). Deriving from the artistic landscape of conceptual installation art and its interactions with science, Winterson's 2019 novel Frankissstein borrows the subject of the nature morte and adopts a metafictional framework to address the clashes between artificial life forms and human civilisation. For instance, she alludes to artworks such as those of Damien Hirst when writing about cryonic bodies: 'It's a little like an art installation in here isn't it? Have you seen Damien Hirst's pickled shark in a tank?" (106). Based on the interdisciplinary interrelations between installation art and contemporary literature, this paper will read the dialogue between Winterson's ekphrastic subject of the nature morte in Frankissstein and contemporary installation art (including works of Hirst, Cai Guo-Qiang, and Guillaume Paris) as a response to the rise of artificial life forms, with respect to their metafictional and illusional nature as AI will become "fully self-designing" (Winterson 73).

\footnotetext{
${ }^{1}$ Nature Morte is literally translated as 'dead nature.'
} 


\section{Da Vinci's Pickle Jars: The Hyperreality of Death}

As mentioned, the subject of the nature morte has a long history. Leonardo da Vinci was one of the first to turn away from Christian allegories and instead show a "surgical clarity of vision" by focusing on "mechanical and biological functions" (Petry 9) of the human body with measurements and observations as in Studies of the Foetus in the Womb (c. 1510-1513). Contemporary artists and writers have been making use of Da Vinci's anatomical approach to the mechanism of human bodies, that is, to illustrate the "human machine like other machines" and demonstrate "the mechanical principles underlying all the living movements from birth to death" (Keele 195). This allows artists to explore the ethical issues around our scientific attempts to eternally preserve the human body with cryonics and replace 'damaged components' like machines.

The artistic representation of the nature morte of human beings with intertextual reference to Da Vinci poses the question of whether cryo-preservations are a way to cheat death and thus reality. In Frankissstein, Winterson sheds light on the transformation of human beings into machines by saying that the "problem with cryonics is that no one knows how to reheat the body without destroying it" and compares the scientific development of cryonics with Da Vinci's drawings of helicopters that were made "centuries before powered flight" (105). Winterson's ekphrastic comparison between cryonics and Da Vinci's drawings of machines criticises how cryonics can only create 'unauthentic' forms of artificial life. Da Vinci's scepticism can be further observed in his illustrated treatise on "Elements of Machines" as he uses Euclid's logical pattern in Elements of Geometry (c. $300 \mathrm{BC}$ ), which is the basis for his bioengineering perspective of the human body as "a mechanical instrument" (Keele 23-37). The intertextual reference to Da Vinci's bio-engineering and geometrical approach brings out the immobility and thus the state of the nature morte in machine-like cryonic bodies as Winterson describes them as "modern-day" mummies with replaceable noses like mechanical components with scientific terms in details (103-106).

To outline her idea of cryo-preservations as an illusion of life, Winterson again draws on Da Vinci's anatomies in the metafictional encounter between Mary Shelley and her character Victor Frankenstein: 
The template for this drawing was Leonardo's The Vitruvian Man (see fig. 2); man the measure of all things, beautiful, proportioned, rational in his beauty. Yet this drawing shared none of the attributes of the original. There were measurements, certainly, and beyond the scale of any human frame; the length of the arms, the width of the face [...] One of the phenomena which had peculiarly attracted my attention was the structure of the human frame. Whence, I often asked myself, did the principle of life proceed? (191192)

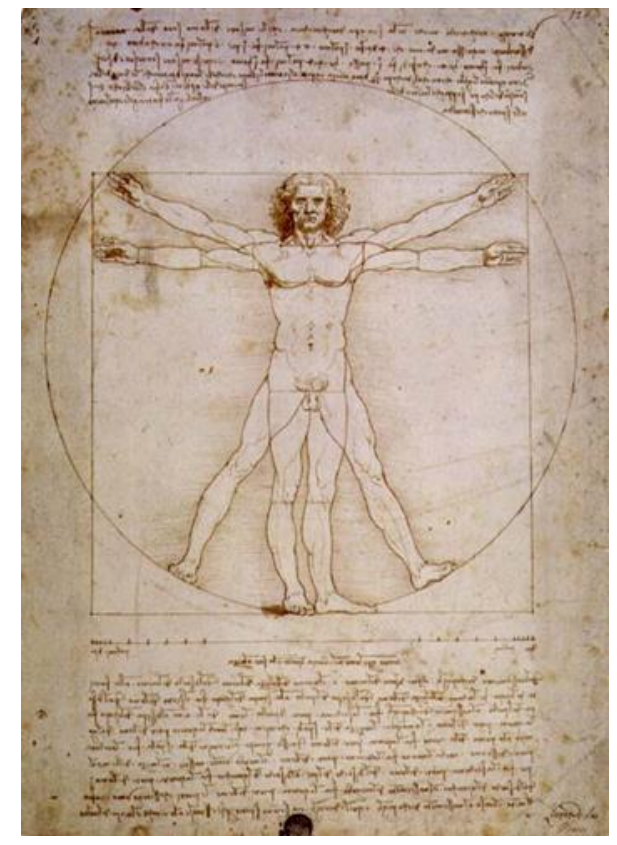

Figure 2. Da Vinci, Leonardo. The Vitruvian

Man. C. 1490, Gallerie dell'Accademia, Venice.

In this passage, the metafictional Victor Frankenstein's approach to drawing the human body is based on Da Vinci's human anatomies. Winterson once again demonstrates the horror of the design of a mechanically perfect human with accurate measurements as the drawing is nothing like the 'natural' original. Not only is Victor's drawing method like Da Vinci's, the latter's “dehumanising” dissection (Giovio 2) uncannily resembles Victor's uses of organs from dead bodies for the creation of his monster as well as the modern Victor Stein's experiments with walking fingers (169). According to his biographer Paolo Giovio, Da Vinci dissects the bodies of criminals to draw on panels the shape of different body parts (2). However, despite his mechanical thinking as seen in his dissections and drawing, his loneliness 
following his charge of homosexuality in 1476 leads him to ask, "if there is no such thing as love what is there?" in one of the sketches in Treatise on Paintings in Codex Urbinas (1632) (4). Winterson dwells on the principle of life too by subtly alluding to Da Vinci's question about love as the core of living with her 'love story' between Mary and Percy Shelley/Ry, the 'modern' metafictional version of the former, and Victor, leaving the readers wondering what makes us 'mobile' and living instead of being in the frozen state of the nature morte like cryonic beings.

Extending from her ekphrastic intertext of Da Vinci's mechanical approach to human anatomies, Winterson further draws on a more contemporary and artistic perspective to the state of the nature morte of cryonic bodies by comparing them to "Damian [sic] Hirst's pickled shark in a tank" (106). Like Winterson, according to his personal website, Hirst explores "the theme of life, death, and human experience" by alluding to Da Vinci as well (Hirst). For example, The Last Supper with Skeletons (2003) (see fig. 3), Hirst's draft for a sculptural appropriation of Da Vinci's The Last Supper (1495-1498), turns the 'living' guests into 'still' human skeletons who are divided by broken sheets of glass.

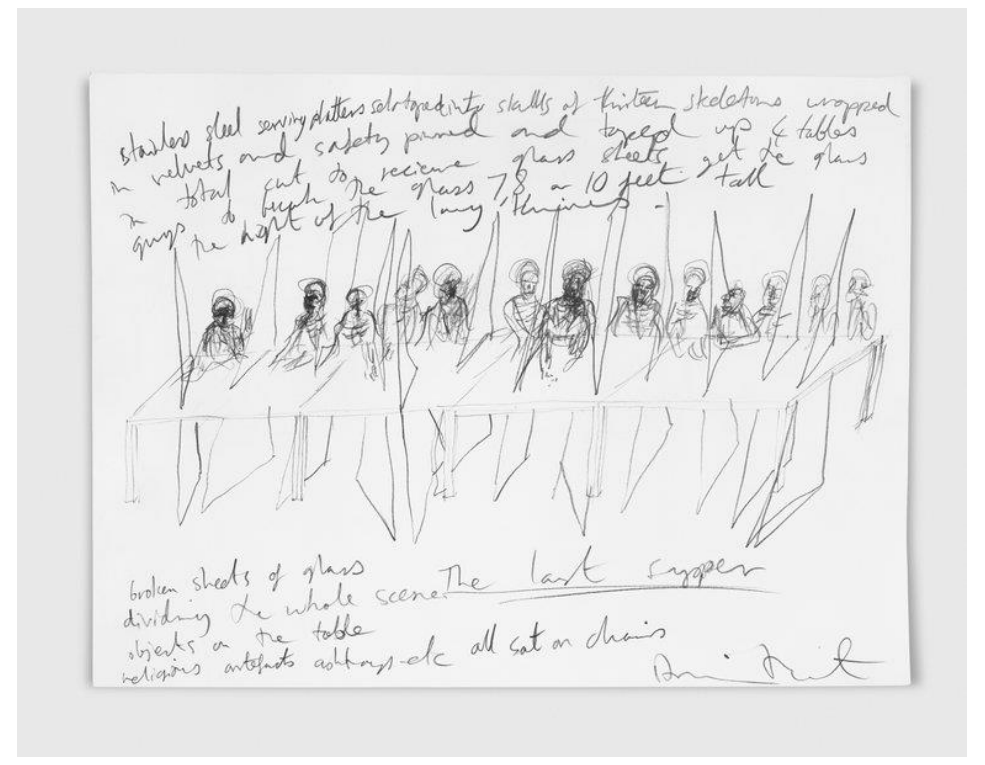

Figure 3. Hirst, Damien. The Last Supper with Skeletons. 2003, Gagosian Gallery, New York.

Da Vinci's The Last Supper has a great influence on Hirst's theme of death embodied in his representation of the nature morte. He brings back Da Vinci's mechanical anatomies with the thirteen skeletons while evoking the presence of Jesus by arranging the skeletons with "an absolutely symmetrical frame leading to the vanishing point" (Tamir 304) as in The Last 
Supper. Highlighted by the clinical atmosphere created by the sheets of glass, the tension between the mechanical and the sublime "constitutes a peculiar spatio-temporal disjunction from its own image" and thus "a mild vertigo of absence and dislocation from" the viewers (White 93). Moreover, the allusion to Judas' betrayal is a representation of human beings using technology to cheat death. Hirst's scientific concept in Skeletons can be seen applied in his collection of pickled nature morte in terms of the idea of the 'clinical glass'.

Winterson further expands on her intertextual comparison of Hirst's The Physical Impossibility of Death in the Mind of Someone Living (1991) (see fig. 4) to a "modern-day mummy from old Memphis" in excellent shape with a broken but fixable chest and nose (106).

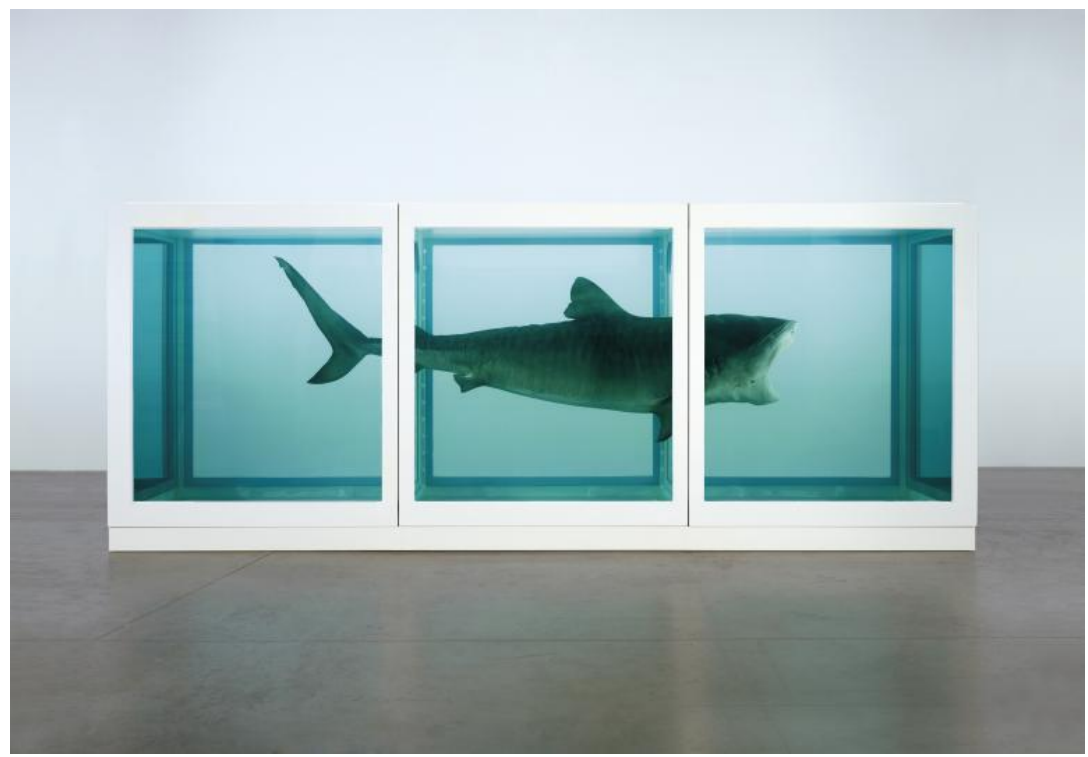

Figure 4. Hirst, Damien. The Physical Impossibility of Death in the Mind of Someone Living, 1991. Tate Modern, London.

Winterson's illustration of the pod for cryo-preservations as "Hotel Vitrification" is an ekphrastic allusion to Hirst's pickled jars as they contain the nature morte of soulless and still "dead men" in a "polished morgue" (103). Hirst's scientific concepts coincide with Winterson's criticism of cryonics as a creation of 'unreal' life forms as Hirst's 'pickled jars' have "connections with conventions of representation in museums of the natural sciences and cultural history" because they are "vitrines filled with objects from nature or man-made artefacts" (Kuuva 132). Through the ekphrastic encounter, Winterson's 'pickled people'

\footnotetext{
${ }^{2}$ I interpret the misspelling of Damien Hirst's name (Damian Hirst) (103) as the superficial reading of art in the contemporary age as Winterson states in "Art Objects" that the Western audience "avoid painful encounters with art by trivialising it, or by familiarising it" (11).
} 
"engage critically with the crisis of representation while displacing this engagement onto another art form" (Bremm 9). Thus, through highlighting the 'soulessness' of the pickled, she also conveys the idea of "the spirit" having already left the body even though "man-made medicine maintains the metabolic process of breathing" (Kuuva 134). In this sense, Winterson's intertextual references to Hirst and their mutual comparisons between Da Vinci's mechanical approach to the human body and modern life-extending technology mocks our selfdeceptive attempt to avoid the "inevitability of death" (105), as implied by the "poetic clumsiness" of the title of Hirst's pickled shark that expresses "something that wasn't there, or was there" (Burn \& Hirst 184-191). As stated by Hirst in his interview with Hans Ulrich Obrist, the unnatural setting of a pickled shark or human body forces "the viewer out of their element by introducing into a gallery setting" a still human or shark that is "real enough to frighten you" (Hirst), which makes death unavoidable to us even with cryonics. By portraying the nature morte of "transhuman" in vitrine-like glass cylinders (Winterson 104) or 'transshark' in a vitrine, both Hirst and Winterson confront their audiences with the closeness of death, while exploiting the medium to "demarcate spaces, to delineate boundaries" that impose a physical barrier that cannot be transcended (Poste 100). Therefore, a space of hyperreality with the paradoxical intimate encounter between the living and the dead/still is created, paralleling "the virtual reality in which we live, structured by information and technology, is sustained on an amalgamation of elements which were previously separate" (Thiry-Cherques 2). In this sense, we are bound to be merely nature morte by turning ourselves into the "transhuman" through the means of "genetic modification, prosthetic enhancement," even living forever as a "brain emulation," because we will feel that "we're in the wrong body" (104).

\section{Artificial Intelligence: The Illusional Parallel Life Forms}

Apart from drawing direct allusions to Hirst's visuality and Da Vinci's scientific concepts, Winterson's metafictional framework also borrows from the "meta-critical and selfreflexive art process" (Shanken 434) of techno-nature art installations to portray the illusion of parallel life forms. As Winterson notes, "[when] an AI can fool us into thinking it's human during a conversation - an enhancement of the kind of conversation you have now with Siri, or Ramona, or Alexa, or any other chatbot - then we will have reached parallel life forms" (150). The metafictional framework in contemporary art criticises the scientific pursuit to 
imitate human life with artificial intelligence and thus projects the ontological question about the difference between 'authentic' life forms and the nature morte.

Firstly, Winterson's representation of disembodiment between the brain and the physical body can be compared to the virtual worlds in contemporary digital installation. At the end of the novel, Winterson reveals that the several metafictional realities of Ry's modern universe, Mary Shelley's life, and her encounter with Victor are all virtual projections as Shelley feeds the "punch-card into" the Analytical Engine to "read back to life" (344), hinted by an earlier line: "Reality is not now" (197). By portraying the 'living' as merely illusional images stored in a 'dead' memory card, the 'restored life-like' human once again turns into the nature morte. Likewise, contemporary artist Guillaume Paris' digital film installation still Out of the Whale (2008) (see fig. 5) shows Carlo Collodi's fictional character Pinocchio eternally floating face down in a pool of lava-like liquid, which mocks how human beings try to imitate 'inauthentic' life through technological means.

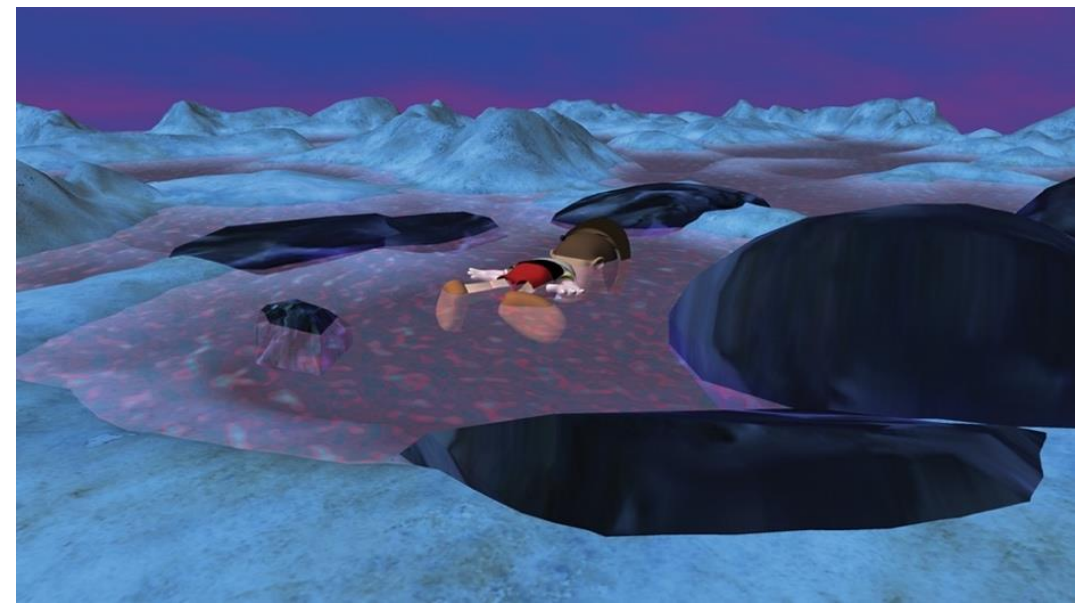

Figure 5. Paris, Guillaume. Out of the Whale. 2008, Espace Multimédia Gantner, Bourogne.

Paris' Out of the Whale not only intertextually and metafictionally alludes to Pinocchio's lies as well as his paradoxical ontological status as a living puppet, but also makes use of digital images to convey his cautionary message about artificial intelligence. Just as Winterson warns that "Humankind cannot bear very much reality" (55) as AI becomes more and more capable of creating highly realistic virtual communities, Paris addresses the same theme in Whale. In his brochure for the exhibition "H.U.M.A.N.W.O.R.L.D." (1999), he elaborates the state of the nature morte of his animated Pinocchio: AI is developing its own 
autonomy as we continue to humanise it and facilitates the design of a virtual world that enables the "flourishing of the avatars of the Meta-Community" (Paris) and the monster "cannot be unmade" once made (Winterson 217). Paris' emphasis on virtual reality taking over coincides with Winterson's cautionary tone as Ry notes that it is terrifying to "revive a 'dead' brain" as the "brain would not have a functioning body" without being aware of the face (188). In this sense, Winterson borrows the notion of "body-mind disconnect" from animated art installation to turn the human body into the nature morte while the brain makes us foolishly believe that we are 'mobile' when this "world of ours is a simulation" (294). Therefore, Winterson's metafictional memory card, like Paris' animation, breaks down our connection to our "physical reality" (188) as we "cheat death in a virtual domain" (Petry 240) and create a MetaCommunity with AI.

Extending on her idea of a virtual Meta-Community, Winterson asks readers the question of what makes us different from the projected hologram-like human images by AI as she writes "if you are talking embodied artificial intelligence - I am not sure we will be able to tell who or what is human and who or what is not" (150). Broersen and Lukács' Time and Again (2011) (fig. 6) explores the same ontological concern with a digital video projection of a blooming yet decaying lily formed of merely digital codes instead of DNA, which is "a digital manifestation that lives and dies, and yet never achieves a real existence" (Petry 58) like Victor Stein's perception of ourselves "as data [...] the sum of who you are" (Winterson 266).

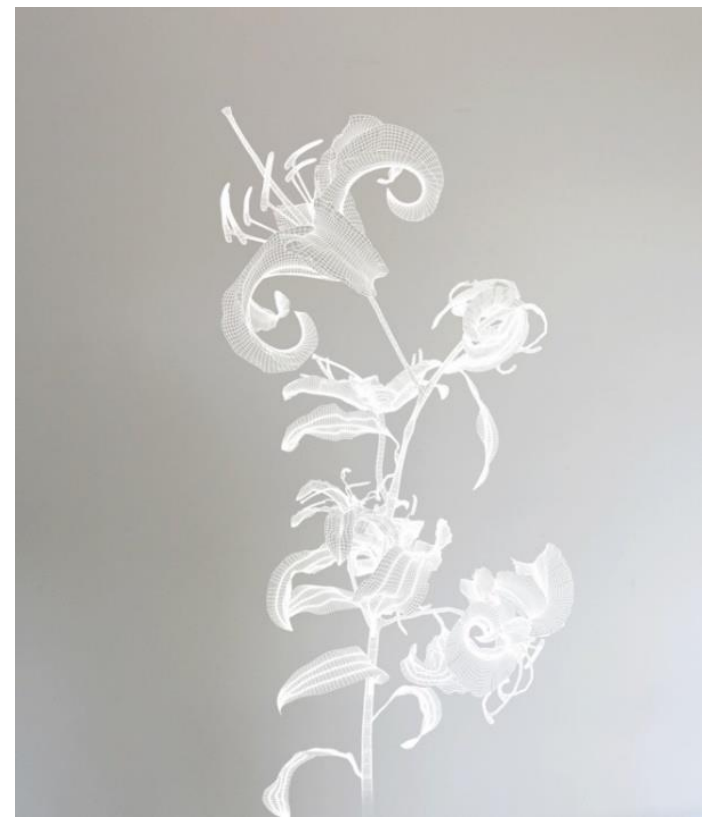

Figure 6. Broersen, Persijn and Margit Lukács.

Time and Again, 2011. Domusdela, Eindhoven. 
By projecting "dematerialised physical objects into visual representations" onto screens, Time maintains the "dematerialist trend of first-wave conceptual art" (Ilfeld 60-1) and stresses Jean Baudrillard's videotaped question in 1988: “Am I man, or am I a machine?” (135). Although Broersen and Lukács use the nature morte of flowers instead of human beings, the same postmodern sensibility of the blurred definition between men and virtual projections can be seen in Frankissstein as Winterson asks "what is your substance, whereof are you made/ That millions of strange shadows on you tend?" (341). By stating how absurd it is that "we are vanished without trace" like Shelley's metafictional character from the locked room, the mind becomes "a screen and on the other side of the screen there is a being seeking life" like a simulation $(67,304,341-344)$. In this sense, both Winterson's narrative and Broersen and Lukács' work make use of the conceptual idea of metafictional hologram-like images of the nature morte to portray the intangibility and inauthenticity of AI-made 'human beings' in the form of digital codes. The emphasis on hollowness resonates with Deleuze and Guattari's notion of "Body-without-Organs" that suggests that "a [mechanical] body may be structured like an organism" but will "always retain the capacity to "disarticulate"" and "cease to be an organism" (Smith 109). Such a notion echoes Winterson's existential pondering as all humans will be generated by energies and thus become "chimerical illusions" and "impossible to realise consistently through time and across space" (151). As Winterson notes, we "compose a man, larger than life, and make him live [...] rod him with fire like Prometheus" to "steal life from the gods" (67) [...] "That is the dilemma [...] I do not know if I am the teller or the tale" (194) - the shift from our physical reality to a virtual one creates a sense of ambiguity and urges us to reconsider what makes us the living in contrary to the 'fake reality' of AI.

\section{The Collective Human Pack: The Past and Future Dream at the Moment of Suspense}

Expanding on the focus on the relationship between a single human body with artificial intelligence, Winterson touches on the question of the future disaster produced by the collective "human dream" (344) on a societal level as we attempt to shape the collective future of humanity with technology. Through making use of the conceptual idea of the nature morte, Winterson places her narrative in dialogue with installation art as she alludes to a particular 'still' scene of a mythical disaster to remind us of our self-destructive nature present throughout human history. 
To evoke the imagery of the biblical doomsday, Winterson alludes to Noah's Ark as her characters Ry, Ron, Claire, and Polly are in their "own little ark" (297) when Victor attempts to "free from the body" to "complete the human dream" by flooding the "earth" and let AI simulate a 'brand new' illusional reality with the data of our brain (294-297). Winterson does not follow the scene immediately with flooding but instead with Mary Shelley's metafictional narrative and the group drinking "warm beer" in a "replica of a 1950s pub" (309), which leaves the readers in suspense and thus dwelling on the specific moment of awaiting 'the end of the world.' This moment of suspense achieves what Winterson describes as 'increasing discomfort" when we look at a piece of artwork with unusual concentration (9). She further explains that as contemporary artists reclaim the past and connect the past "to the future," the "other world" that the artwork implies "challenges the 'I' that we are" (12-15). Thus, the conceptual idea of considering all human individuals as a whole makes us reflect on the selfdestructive nature of the collective 'us' throughout human history.

Reading Winterson's 'still' scene of the genesis as a metaphor of the new age of AI under the theoretical framework of the collective human history in contemporary art as elaborated above, artist Gabriel Orozco's whale sculpture Dark Wave (2006) (see fig. 7) also alludes to a biblical scene in which Jonah is swallowed by a whale when he denies God's prophecy of the end of the wicked city of Nineveh.

The whale's skeleton is painted with a pattern of grids in graphite and made of the real

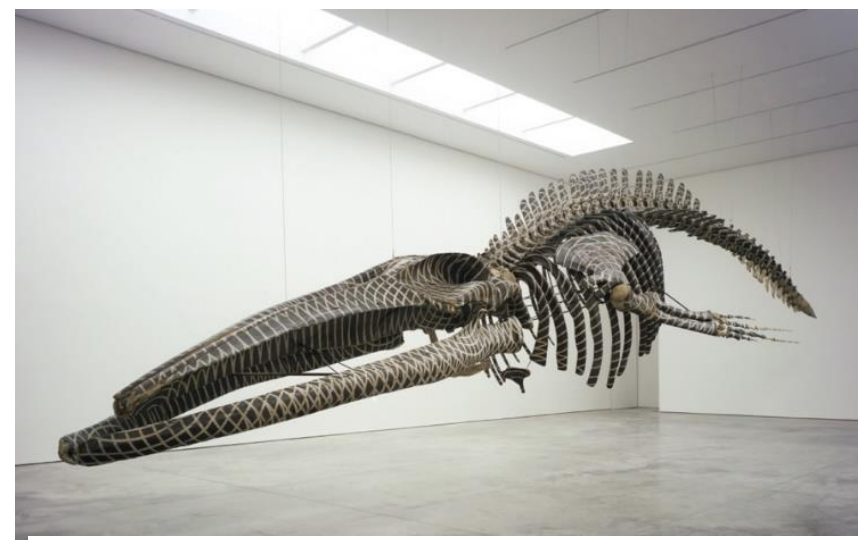

Figure 7. Orozco, Gabriel. Dark Wave. 2006, White Cube, London.

bones of a rorqual whale "found on the south-west coast of Spain" (Petry 280). Reading into Orozco's aesthetic, the presence of death is highlighted by the bone-structure of the whale as 
it is 'still' and the Renaissance representation of whales as symbols of the devil and their mouths as the entrance to hell (Petry 80), again giving the viewer a sense of suspense with the state of the nature morte. With the grid-pattern and the arrangement of the bones in overlapping "concentric circles" upon "a number of pivotal points," the viewers are under the impression that volume is made graphic and object is made image due to the "application of a loose intuitive system", and thus "a certain degree of intimacy transpires" (Coles 23). In this sense, while the colour contrast and geometric patterns of the whole installation evoke a futuristic mood, the underground location of the sculpture in the White Cube gallery's Mason's Yard building and the archaeological approach to collecting bones connect the viewers to the longlost ancient age. Orozco's connection between the 'mythical' past and the future parallels that of Winterson as she questions if the old "human dream" of eternity will lead to our end: "I wondered, what will become of the human dream? Will we see it end in pain and despair [...] By some artful intelligence [...]?" (256-257). Therefore, they both remind us that we will face the collective fate of self-destruction if we continue to "undercut Nature as keeper" (Dixon 686) with technology because "human beings really don't have a better chance than AI" and we have never created something "that is perfect" even we start with the best intentions (Winterson 264-265).

Some artists address the theme of human beings' collective nature of self-destruction with the nature morte of life-like pack animals ${ }^{3}$. Placed in still motion such works emphasise "mortality and the imminent death of all living creatures," which warn of the foolish thought that death can be cheated with technology, as "death stalks us all" (Petry 179). Cai Guo-Qiang's Head On (2006) (see fig. 8) features ninety-nine stuffed wolves crashing on a glass wall in a wave-like circular structure. The number ninety-nine signifies an "incomplete' rather than a round number, suggesting something more to come" (Pagliarino, Storer, \& Wild 256), which coincides with Orozco's and Winterson's moments of suspense featured in a second away from the ultimate disaster for human beings. In addition, while the pack nature of wolves and crashing motion reminds us of "society's collective ability to hurl itself toward disaster" (Petry 192), Cai's screen of glass not only evokes the image of the Berlin Wall ${ }^{4}$ but also gives the viewer a technological aspect like Hirst's transparent screens in Physical Impossibility and Winterson's cryo-pods. Therefore, Cai also establishes a connection between the past and the

\footnotetext{
${ }^{3}$ Note that the term 'animals' here refers to life-imitating ones in art instead of the mythical symbol of a biblical narrative as seen in Gabriel Orozco's whale sculpture Dark Wave.

${ }^{4}$ Cai prepared his creation of Head On by visiting the remains of the infamous Berlin Wall and Checkpoint Charlie. His work was also first showcased at Deutsche Guggenheim in Berlin.
} 
future to engage with the idea of human beings destroying their own civilisation on repeat in 'circular patterns' under the illusion of "the body that must fail and fall is not the end of the human dream" (Winterson 264), just like Mary Shelley 're-playing' her "invention that sits inside another invention - reality itself" (345) with a punch-card.

\section{Conclusion}

The contemporary is always in flux and the "new, disorienting" speed of technological development conditions the materials and aesthetic forms in which we experience the present

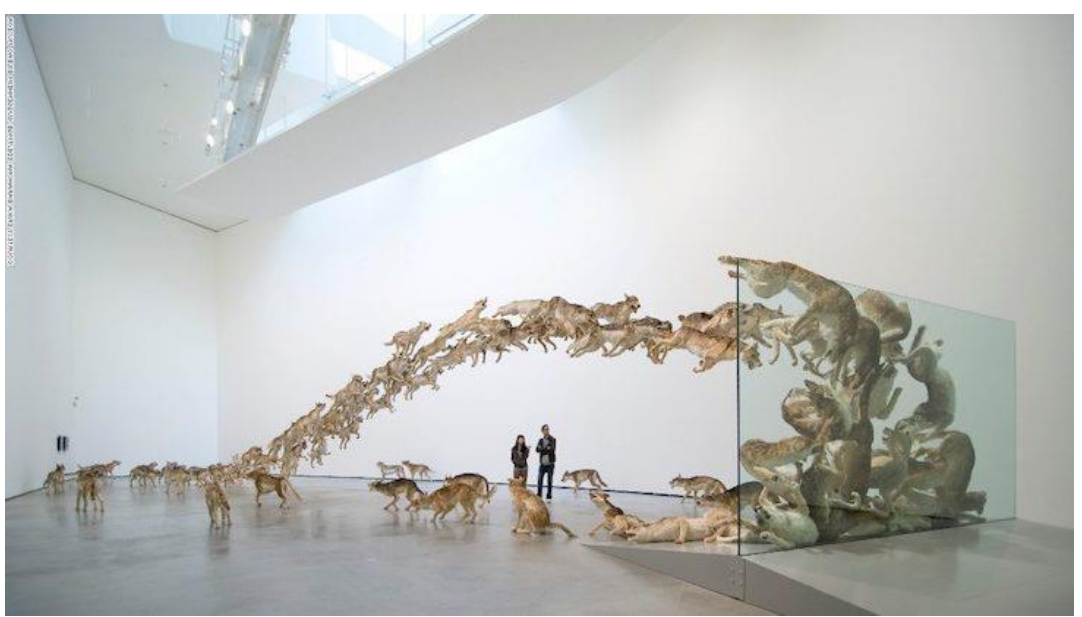

Figure 8. Cai, Guo-Qiang. Head On. 2006, Deutsche Guggenheim, Berlin.

(Boxall 3); therefore, the artistic vision of the posthuman future will always change as new AI technologies emerge. Contemporary artists and writers will continue to explore the "boundaries between the artificially made and natural in connection to human existence" (LeGrandeur 388) by connecting the past to the future through new forms of experimentation as Winterson states in "Art Objects". This is done by a matter of fact, by revisiting the tradition of the nature morte in the history of art, artists and writers reflect on the ever-changing definition of living and being human throughout human history. Therefore, we are witnessing the technological transformation of our very selves by examining experimentations across art and science as "what it means to be human will not be determined any longer merely by your biological structure but perhaps also determined largely by all of the technology" (McCafferty). As we read the influences of installation art on Winterson in this paper, we can expect literary texts will employ more conceptual art practices through the literary device of ekphrasis to transfer "the discussion of the problem of verbal representation" to the description of art (Bremm 8) to search for new artistic representations to encode "the estranged material conditions of 
posthuman embodiment" (Boxall 13) in the contemporary age when science becomes a huge part of our existence. Seeing the contemporary as a fluid construct, Winterson beautifully demonstrates the interweaving nature between different fields of arts as a response to the changes between eras and as a reflection on the fast-paced technological world, making Frankissstein a hybrid of the visual arts, technologies, and fictional writing. 


\section{Works Cited}

Bandello, Matteo, Paolo Giovio and Giorgio Vasari. Lives of Leonardo Da Vinci (Lives of the Artists). J. Paul Getty Museum, 2019.

Baudrillard, Jean. Simulacra and Simulation (The Body in Theory: Histories of Cultural Materialism). University of Michigan Press, 1994.

Boxall, Peter. Twenty-First-Century Fiction: A Critical Introduction. Cambridge UP, 2003.

Bremm, Doris. Representation Beyond Representation: Modes of Ekphrasis in Contemporary Literature. 2007. University of Florida, PhD dissertation. ProQuest, proquest.com/docview/1941145027.

Broersen, Persijn and Margit Lukács. Time and Again. 2011, Galerie AKINCI, Amsterdam.

Burn, Gordon and Damien Hirst. On the Way to Work. Faber \& Faber, 2001.

Cai, Guo-Qiang. Head On. 2006, Solomon R. Guggenheim Museum, New York.

Coles, Alex. "Review: Gabriel Orozco." Art Monthly, vol. 301, 2006, pp. 22-23. Gale, link.gale.com/apps/doc/A159863938/AONE?u=ed_itw\&sid=AONE\&xid=a8a5f117.

Crowther, Paul and Isabel Wünsche. Meanings of Abstract Art: Between Nature and Theory. Routledge, 2012.

Da Vinci, Leonardo. Studies of the Foetus in the Womb. 1511, The Royal Academy of Arts, London.

Da Vinci, Leonardo. The Last Supper. 1490s, Convent of Santa Maria delle Grazie, Milan.

Da Vinci, Leonardo. The Vitruvian Man. C. 1490, Gallerie dell'Accademia, Venice.

Da Vinci, Leonardo. Treatise on Paintings. Dover Publications, 2005.

Deleuze, Gilles and Félix Guattari. A Thousand Plateaus: Capitalism and Schizophrenia. University of Minnesota Press, 1987.

Euclid. Elements of Geometry. Palala Press, 2016.

Hirst, Damien. The Last Supper with Skeletons. 2003, Gagosian Gallery, New York.

Hirst, Damien. “The Last Supper with Skeletons, 2003." Damien Hirst, Damien Hirst and Science Ltd, 2012, damienhirst.com/the-last-supper-with-skeletons. 
Hirst, Damien. The Physical Impossibility of Death in the Mind of Someone Living. 1991, Steven A. Cohen, New York.

Hirst, Damien. Interview. Conducted by Hans Ulrich Obrist, 2007, damienhirst.com/texts/20071/feb--huo.

Ilfeld, Ethan J. "Contemporary Art and Cybernetics: Wave of Cybernetic Discourse Within Conceptual, Video and New Media Art." Leonardo, vol. 45, no.1, 2012, pp. 57-63. JSTOR, jstor.org/stable/41421795.

Jameson, Fredric. Postmodernism, or, the Cultural Logic of Late Capitalism. Verso, 1991.

Keele, Kenneth D. Leonardo Da Vinci's Elements of the Science of Man. Academic Press, 2014.

Krieger, Murray. Ekphrasis: The Illusion of the Natural Sign. Johns Hopkins UP, 2019, pp. 232-261. Project MUSE, doi.org/10.1353/book.68495.

Kuuva, Sari. "A Metabolism of Adam and Eve: Damien Hirst meets Edvard Munch." Art Approaching Science and Religion, vol. 6, no.2, 2016, pp. 125-135. Approach Religion, doi.org/10.30664/ar.67597.

LaGrandeur, Kevin. "Art and the Posthuman.” Posthumanism: The Future of Homo Sapiens. Edited by Michael Bess and Dian Walsh Pasulka, Macmillan Reference USA, 2018, pp. 377388.

Latham, William. Mutation X Raytraced. 1991-1992, Mutation VR, mutatorvr.co.uk/portfolio/mutation-X-raytraced-blue-william-latham1992/?portfolioCats=35.

McCafferty, Georgia. "The Man With an Ear on His Arm.” CNN, 13 August 2015, www. edition.cnn.com/style/article/stelarc-ear-arm-art/index.html.

Memling, Hans. Vase of Flowers. C. 1480, Museo Thyssen-Bornemisza, Madrid.

Orozco, Gabriel. Dark Wave. 2006, White Cube, London.

Pagliarino, Amanda, Russell Storer and Elizabeth Wild. "Conservation From Conception: Commissioning an Installation by Cai Guo-Qiang." Studies in Conservation, vol. 61, no. 2, 2006, pp. 255-9. Taylor and Francis Online, doi.org/ 10.1080/00393630.2016.1183098.

Paris, Guillaume. Out of the Whale. 2008, Espace Multimédia Gantner, Bourogne. 
Paris, Guillaume. H.U.M.A.N.W.O.R.L.D., www.guillaumeparis.com/work.html.

Petry, Michael. Nature Morte: Contemporary Artists Reinvigorate the Still-Life Tradition. Thames \& Hudson, 2013.

Poste, George. "Revealing Reality Within a Body of Imaginary Things." Theories, Models, Methods, Approaches, Assumptions, Results and Findings. Edited by Jason Beard, Other Criteria, 2008, pp. 97-115.

Shanken, Edward A. "Art in the Information Age: Technology and Conceptual Art.” Leonardo, vol. 35, no. 4, 2002, pp. 433-8. JSTOR, jstororg.ezproxy.is.ed.ac.uk/stable/1577407?sid=primo\&seq=1\#metadata_info_tab_contents.

Shields, David. Reality Hunger: A Manifesto. Knopf, 2010.

Smith, Daniel. "What is the Body Without Organs? Machine and Organism in Deleuze and Guattari." Cont Philos Rev, vol. 51, 2018, pp. 95-110. Springer, doi.org/10.1007/s11007-0169406-0.

Tamir, Abraham. "'The last supper': Past-da vinci, present-nes."The Canadian Journal of Chemical Engineering, vol. 79, no.2, 2001, pp. 304. Wiley Online Library, doiorg.ezproxy.is.ed.ac.uk/10.1002/cjce.5450790215.

Thiry-Cherques, Hermano. "Baudrillard: Work and Hyperreality." Eletrônica, vol. 9, no. 2, 2010, pp. 1-11. ProQuest, proquest-com.ezproxy.is.ed.ac.uk/scholarly-journals/baudrillardwork-hyperreality/docview/821638122/se-2?accountid=10673.

Virilio, Paul. Open Sky. Translated by Julie Rose, Verso, 1997.

Warhol, Andy. Ten-Foot Flowers. 1967, MoMA, New York.

Winterson, Jeanette. Art Objects: Essays on Ecstasy and Effrontery. Jonathan Cape, 1995.

Winterson, Jeanette. Frankissstein. Vintage, 2019.

White, Luke. Damien Hirst and the Legacy of the Sublime in Contemporary Art and Culture. 2009. Middlesex University, PhD dissertation. ProQuest, proquestcom.ezproxy.is.ed.ac.uk/docview/1040405788?pq-origsite=primo. 


\section{Author Biography}

Audrey Chan is a postgraduate student completing MSc Literature and Modernity: 1900 to the Present at the University of Edinburgh. Her research interest lies in the interdisciplinary studies between contemporary literature and the visual arts. She also received a bachelor's degree of arts from City University of Hong Kong's Department of English and is now a reader for fiction at UoE's James Tait Black Prize. She has recently presented her paper "Alberto Breccia's Parody of Futurist Paintings in Modern Bande Dessinée: Resisting Transatlantic Fascism" at the conference Transitions 9, and her flash paper "Haruki Murakami's Rhizomatic Underground: Traumatic Memory and New Journalism" at Contemporary Studies Network's conference. Her book review of Matthew LeVay's Violent Minds: Modernism and the Criminal (2019) will also be published in the journal Crime Fiction Studies. 